\title{
Editorial
}

\section{Recent Advances in Biomedical Applications}

\author{
Alberto Borboni, ${ }^{1}$ Tadeusz Mikołajczyk, ${ }^{2}$ and Vera Murgul $^{3}$ \\ ${ }^{1}$ Mechanical and Industrial Engineering Department, Università degli Studi di Brescia, Brescia, Italy \\ ${ }^{2}$ Production Engineering Department, UTP University of Science and Technology, Bydgoszcz, Poland \\ ${ }^{3}$ St. Petersburg State Polytechnical University, Saint Petersburg, Russia
}

Correspondence should be addressed to Alberto Borboni; alberto.borboni@unibs.it

Received 31 August 2016; Accepted 31 August 2016

Copyright (C) 2016 Alberto Borboni et al. This is an open access article distributed under the Creative Commons Attribution License, which permits unrestricted use, distribution, and reproduction in any medium, provided the original work is properly cited.

As widely experimented in research and in real world application, the biomedical field is experimenting different innovations, which are associated with the contamination with the knowledge of other research branches, such as material science, engineering, biological systems, and informatics. Different technical journals proposed special issues in recent years on applications of special technologies for biomedical applications and the number of these special issues increased especially in the last ten years. For this reason, we proposed a special issue, more generally on biomedical applications, with the purpose of seeing how the land lies in these territories of the research. The result of this activity is not surely sufficient to trace the state of the art of biomedical applications but can probably help to identify some field of activity.

Different works are devoted to the analysis (A. Struzik et al.) and to the recovery of functional activities associated with the limbs. In fact, different subjects can be injured by one or more pathologies and they can lose some of their abilities. To recover these abilities, researchers proposed new orthoses for both the lower limbs (A. Rastegarpanah et al. and F. Aggogeri et al.) and the upper limbs (G. Baronio et al.).

Some functional parts of the human body can lose their functionalities in an irreversible way, so they must be substituted to reduce pain, to recover functionalities, and to prevent worsening of patient's conditions. The work of J. O. Figueroa-Cavazos et al. is addressed to this direction.

The accurate evaluation of the pathologies needs new instrumentation and new methodologies, as suggested by V. F. Dinevari et al., or innovative processing technologies, such as $3 \mathrm{D}$ printing (J. O. Figueroa-Cavazos et al. and G. Baronio et al.).
A particular branch of research is devoted to orthodontic applications of manufacturing technologies (N. Ozkalayci and M. Yetmez) and material science (H.-N. Kuo et al.).

We hope that this special issue can contribute to the discussion of the scientific community to focus on some routes of the research and to enhance some gaps that can be filled in future works.

Alberto Borboni
Tadeusz Mikołajczyk
Vera Murgul




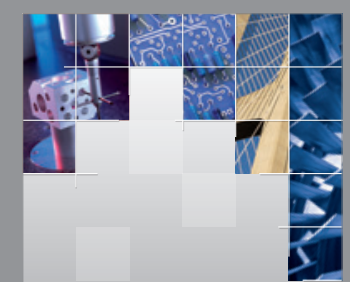

\section{Enfincering}
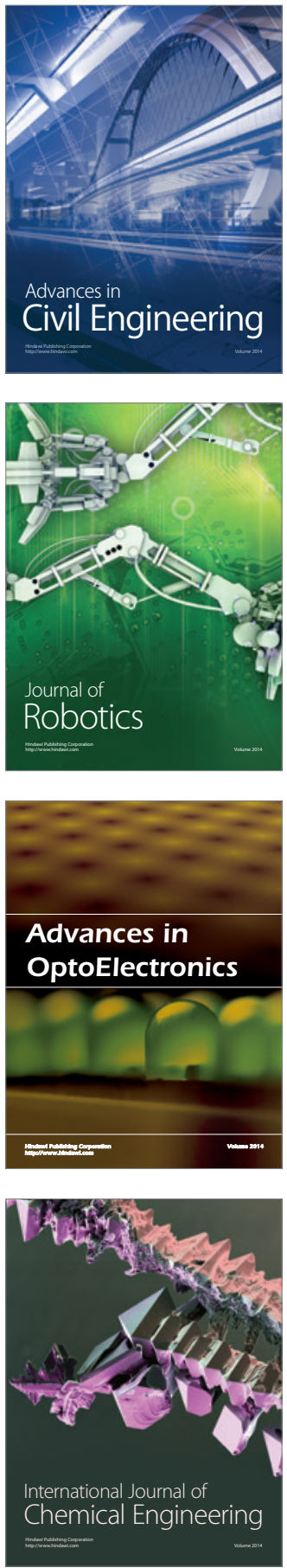

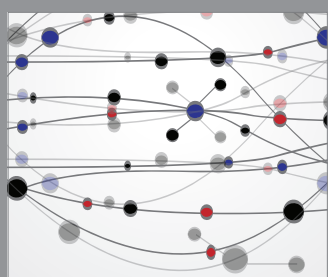

The Scientific World Journal

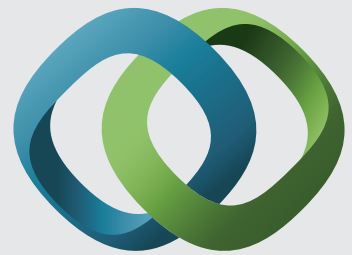

\section{Hindawi}

Submit your manuscripts at

http://www.hindawi.com
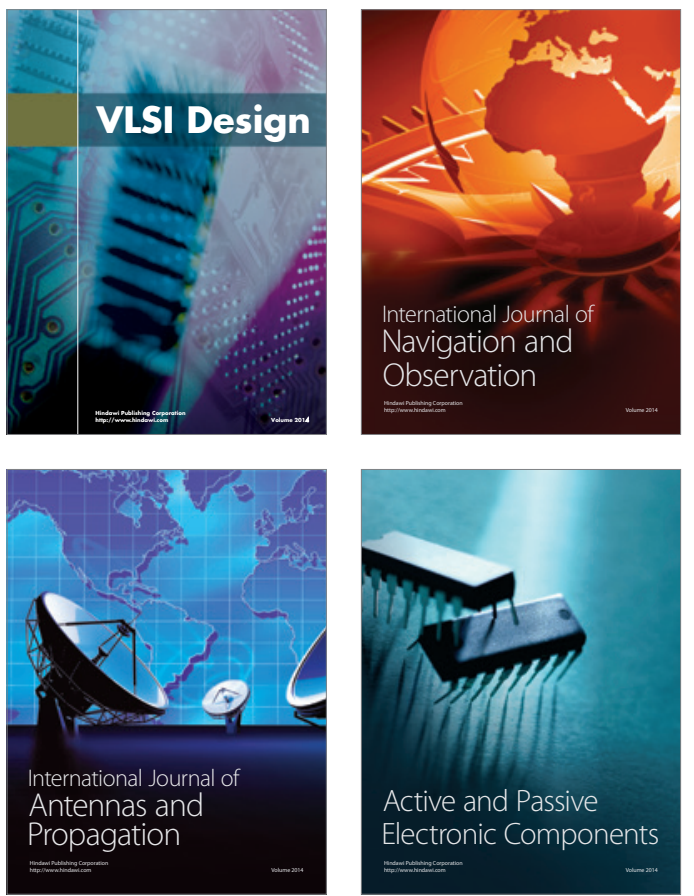
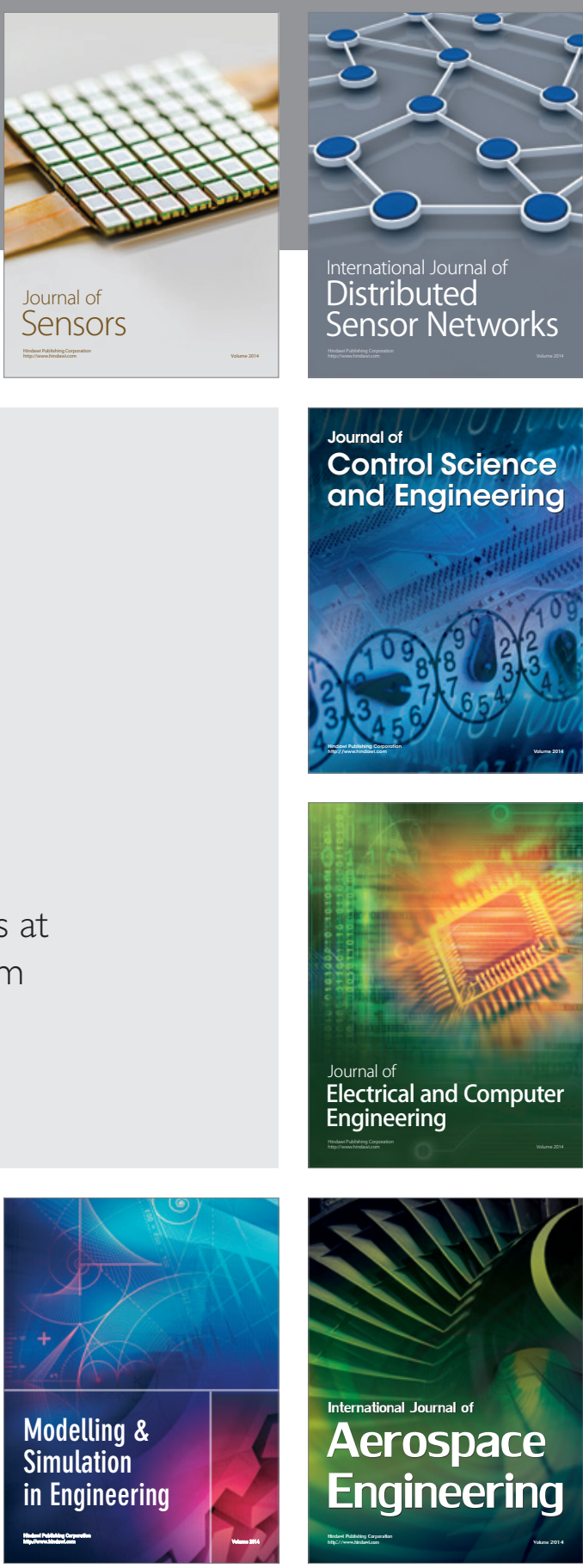

International Journal of

Distributed

Sensor Networks

Journal of

Control Science

and Engineering
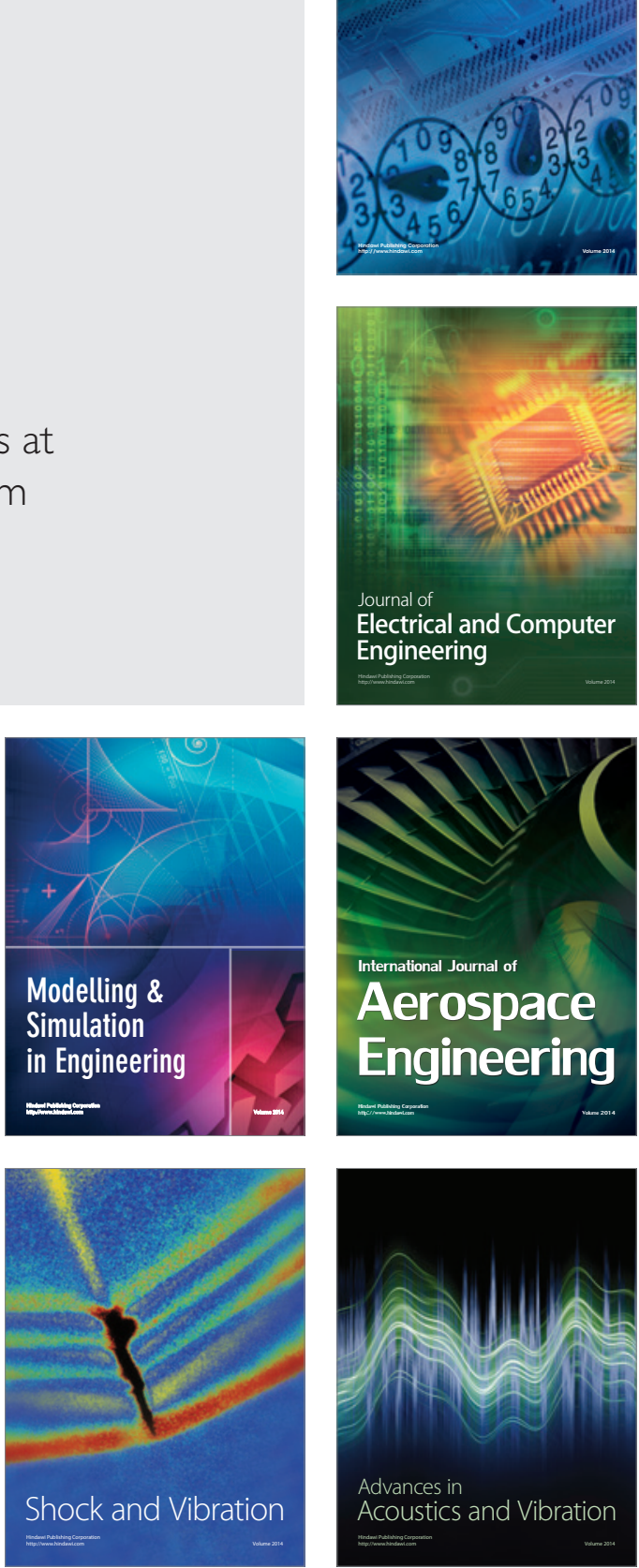